\title{
Advances in retina imaging as potential biomarkers for early diagnosis of Alzheimer's disease
}

\author{
Ying Zhang ${ }^{1}$, Yanjiang Wang ${ }^{2}$, Ce Shi ${ }^{1}$, Meixiao Shen ${ }^{1 *}$ (D) and Fan Lu $^{1 *}$
}

\begin{abstract}
As the most common form of dementia, Alzheimer's disease (AD) is characterized by progressive cognitive impairments and constitutes a major social burden. Currently, the invasiveness and high costs of tests have limited the early detection and intervention of the disease. As a unique window of the brain, retinal changes can reflect the pathology of the brain. In this review, we summarize current understanding of retinal structures in $A D$, mild cognitive impairment $(\mathrm{MCl})$ and preclinical $A D$, focusing on neurodegeneration and microvascular changes measured using optical coherence tomography (OCT) and optical coherence tomography angiography (OCTA) technologies. The literature suggests that the impairment of retinal microvascular network and neural microstructure exists in $A D, M C l$ and even preclinical $A D$. These findings provide valuable insights into a better understanding of disease pathogenesis and demonstrate that retinal changes are potential biomarkers for early diagnosis of $A D$ and monitoring of disease progression.
\end{abstract}

Keywords: Alzheimer's disease, Mild cognitive impairment, Optical coherence tomography, Optical coherence tomography angiography, Retina, Biomarkers, In vivo imaging

\section{Background}

Alzheimer's disease (AD) is a leading cause of dementia and the most common chronic neurodegenerative disease leading to cognitive impairment in the elderly. $\mathrm{AD}$ is pathologically characterized by abnormal extracellular senile plaques consisting of amyloid-beta $(A \beta)$ peptide and intracellular neurofibrillary tangles composed of hyperphosphorylated tau protein. Other disease-specific signs include cerebral amyloid angiopathy resulting from amyloid deposition on microvascular walls, neuron and synaptic loss, inflammation, and gliosis [1-4]. It has been estimated that by 2050 up to 131 million people would suffer from AD [5]. Despite the advances in understanding the pathogenesis and clinical practice over

\footnotetext{
* Correspondence: smx77@sohu.com; lufan@mail.eye.ac.cn

${ }^{1}$ School of Ophthalmology and Optometry, Wenzhou Medical College, Wenzhou 325027, China

Full list of author information is available at the end of the article
}

the past decades, current clinical treatments are limited as most patients have advanced $\mathrm{AD}$ with irreversible neuronal damage. It is generally believed that early intervention can slow the progression of $\mathrm{AD}$. Epidemiologic research has reported that one-year delay in the onset of AD would reduce the projected global burden by 9 million [6]. Therefore, preclinical detection of neurodegeneration will be crucial for preventing dementia caused by $\mathrm{AD}$ and developing new treatments.

Neuroimaging is the most widely used method for early diagnosis of neurodegenerative pathology of $\mathrm{AD}$. With the advent of different neuroimaging technologies, quantitative assessment of cerebral structures and metabolic states in specific regions has become possible. Both magnetic resonance imaging (MRI) and computed tomography $(\mathrm{CT})$ can identify cortical and hippocampal atrophy. In addition, $A \beta$ deposits can be quantified by amyloid positron emission tomography [7, 8]. Besides, 
the cerebrospinal fluid test has been thought to be able to reflect the pathology of AD through decreased amyloid and increased tau levels $[9,10]$. The above methods, however, are invasive, expensive or time-consuming, which may not be suitable for early large-scale screening of $\mathrm{AD}$. Thus, there is an urgent need for an early, noninvasive and cost-efficient tool to identify $\mathrm{AD}$ biomarkers, which could help detect AD pathology in mild cognitive impairment (MCI) stage, even in asymptomatic preclinical AD stage. Such strategy could help predict those at a high risk of developing dementia in a large-scale population.

As a window to the brain, the retina provides a unique opportunity to study the pathophysiology of many ophthalmic and neurodegenerative diseases. A growing body of evidence has indicated that both the brain and the retina are affected in $\mathrm{AD}$ and these pathologic changes are significantly correlated [11]. Some evidence has also shown that the retinal nerve fiber layer (RNFL) thinning, which reflects the loss of retinal ganglion cells (RGCs), is significantly associated with brain atrophy $[12,13]$. The optical coherence tomography (OCT) has enabled the imaging and quantification of RGCs and their axons.

In addition to the neurological defects, evidence has shown that the vascular factors also play a crucial role in the occurrence and development of $\mathrm{AD}[14,15]$. With the advancement of technology, the retinal microvasculature can be visualized and quantified non-invasively using optical coherence tomography angiography (OCTA). Compared to the traditional color fundus photography, OCTA has advantages of visualizing retinal microvasculature at the micrometer level. OCT and OCTA imaging of the retina are potential screening tools for early diagnosis of $\mathrm{AD}$ and identification of the risk of disease progression. In this review, we summarize recent development on the applications of OCT and OCTA as retinal imaging tools to study the pathophysiology of $\mathrm{AD}$ at different stages. We also discuss the clinical implications of these findings and what we can do in future research.

\section{Why is the retina a window to the brain?}

The retina originates from the neural tube as a part of the central nervous system during embryonic development [16]. The RNFL is mainly composed of axons, while the ganglion cell- inner plexiform layer (GC-IPL) mainly contains cell bodies and dendrites. In terms of the brain parenchyma, the white matter of the brain is mainly composed of axons, while the gray matter is mainly composed of cell bodies and dendrites of neurons. Research has demonstrated that thinning of the GC-IPL is significantly associated with the gray matter volume obtained from MRI scans, suggesting that the retinal ganglion cells are potential markers of cerebral neurodegeneration [17].

In terms of the retinal microvasculature around macula, the inner layer of retina is supplied by the ophthalmic artery through the central retinal artery. The ophthalmic artery originates from the internal carotid artery, similar to the intracranial artery. The external retina is supplied by choroid vessels. The blood supply of the optic disc is derived from the posterior ciliary artery circulation, with the retinal circulation supplying the surface nerve fiber layer [18-21]. The retinal arterioles and venules, with diameters from $100 \mu \mathrm{m}$ to $300 \mu \mathrm{m}$, have similar anatomical features and physiological properties with cerebral small vessels, which provides a unique and accessible "window" to study the subclinical microvascular pathology of the brain (Fig. 1).

As one of the main pathological features of $A D, A \beta$ is not only associated with blood vessels but also occurs in the retinal neural structure. Researchers have discovered that the retinal plaques are detectable earlier than those in the brain and accumulate with disease progression in animal models [22]. Koronyo Y and colleagues [11] detected curcumin-labeled $A \beta$ plaques in patients in vivo and showed that the retinal $A \beta$ burden was quantitatively correlated with the amyloid burden in the brain. With regard to other pathological states, patients with raised intracranial pressure often develop optic disc edema, and fundus findings including papilledema and hemorrhage are common in patients with spontaneous subarachnoid hemorrhage [23]. A large standard deviation in retinal arterial width is associated with intracranial arterial stenosis, which indicates that the retinal vessels may provide insights into the cerebrovascular network [24].

\section{Advances in imaging of retinal neural structure and microvasculature based on OCT and OCTA}

OCT is an invasive imaging tool with advantages of high resolution, excellent repeatability, fast scanning speed, and high convenience, which can provide quantitative analyses of individual retinal layers, including the inner boundary membrane, RNFL, ganglion cell layer (GCL), inner plexiform layer (IPL), inner nuclear layer (INL), outer plexiform layer (OPL), outer nuclear layer (ONL), outer membrane, photoreceptor cell layer, and retinal pigment epithelium $[25,26]$. The peripapillary RNFL (pRNFL), which converges to form the optic nerve, is composed of axons of ganglion cells and is thickest around the optic disc. The ganglion cells are mainly concentrated in the macular area. High-resolution spectraldomain OCT also allows measurement of the thickness of the pRNFL, the GCL, the GC-IPL, and the ganglion cell complex (GCC), which is composed of pRNFL and ganglion cell bodies and dendrites. The INL contains cell 


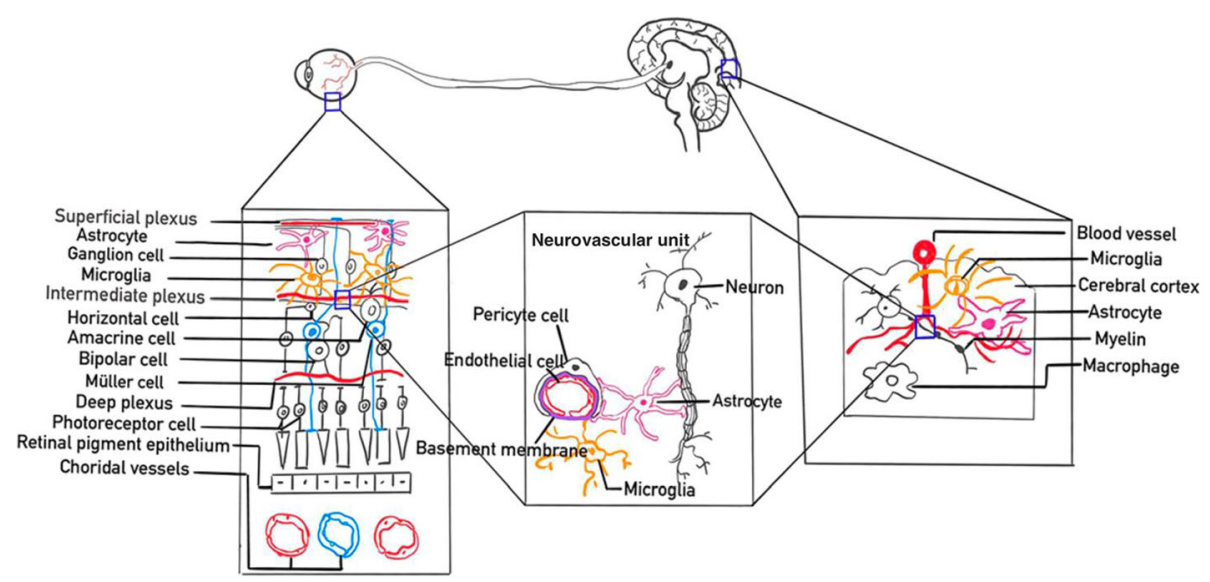

Fig. 1 Schematic diagram of neurovascular units of the retina and brain

bodies of horizontal, bipolar and amacrine cells, and the ONL contains cell bodies of rods and cones. The two neuropils consisting of synaptic contacts divide the above nerve cell layers. The different degrees of light absorption and scattering in individual retinal layers serve as the basis for imaging. Compared with the conventional time-domain OCT devices, the spectral-domain OCT technology offers faster scanning speed and higher axial resolutions. Recently, swept-source OCT has been shown to be more accurate in quantitative segmented retinal layer analyses with increased speed and resolution. The current equipment and built-in software have enabled us to assess the thickness of each retinal layer in different quadrants of macula and optic disc within a minute.

Previous studies based on fundus photography have demonstrated that the quantitative retinal vascular parameters including fractal dimension (FD), central retinal artery equivalent, and central retinal vein equivalent, as well as the qualitative retinopathy, are associated with dementia [27, 28]. Nevertheless, findings from other studies are inconsistent, especially in the early stage of AD [29-32]. This discrepancy may be because that the relatively large blood vessels detected by the fundus camera were not sufficient to reflect the subtle pathology in the early stage of the disease.

As a milestone in the development of retinal imaging technology, the OCTA can detect the movement of red blood cells in the vascular lumen via changes in OCT signal measured by multiple scans in the same cross section. Combined with continuous en-face blood cell movement information, complete three-dimensional imaging of retinal and choroid vessels can be achieved. This is a novel imaging technique that can noninvasively and rapidly depict the microvasculature in different retinal layers with high resolution [33-36]. In addition to the retinal vessel density (VD), FD [37], which represents the retinal capillary complexity, can be obtained from OCTA to detect subtle microvascular changes in the early stage of retinopathies [38] and neurodegenerative diseases [39]. In the following, we summarize relevant studies of OCT/OCTA in AD, MCI and preclinical $\mathrm{AD}$ patients (Tables 1 and 2, respectively).

\section{Changes in retinal neural structure in $A D, M C l$, and preclinical $A D$}

Changes in RNFL and GCC in $A D, M C l$, and preclinical $A D$

The compositions of retinal RNFL and GC-IPL correspond to white and grey matter components of the brain, therefore, they are widely regarded as neural parameters reflecting the progression of $\mathrm{AD}$. At advanced stage of $\mathrm{AD}$, a recent meta-analysis also found a significant reduction in the overall mean pRNFL thickness as well as in the mean pRNFL thickness of all four quadrants [79]. In addition, some studies have reported significant pRNFL thinning in individual quadrants. In most studies, the superior $[41-43,45,49,51,55,61]$ and inferior $[41,43,49,51]$ quadrants showed significantly greater thinning in patients with $\mathrm{AD}$ compared with controls, whereas the temporal $[49,55]$ and nasal $[41,61]$ quadrants were found to be significantly thinner only in a small number of studies. This pattern of quadrantal change in the retina may indicate that the magnocellular ganglion cells located in the extramacular retina are vulnerable to AD pathology [54]. In addition, another explanation is that the concentration of axon bundles is highest in the superior and inferior quadrants [80]. The characteristic quadrantal loss in the RNFL may have better diagnostic efficacy in distinguishing different types of dementia. In a recent study, researchers divided AD patients into different subgroups (mild, moderate and severe $A D)$ and found that the pRNFL degeneration paralleled dementia progression [56]. The pRNFL decreased significantly in the superior quadrant in mild 
Table 1 Studies on OCT parameters in patients with $A D, M C l$ and preclinical $A D$

\begin{tabular}{|c|c|c|c|c|}
\hline Authors & $\begin{array}{l}\text { Year of } \\
\text { publication }\end{array}$ & Layer & Subjects & Alteration \\
\hline $\begin{array}{l}\text { Parisi et al. } \\
\text { [40] }\end{array}$ & 2001 & pRNFL & $A D$ & Thinning \\
\hline Iseri et al. [41] & 2006 & pRNFL, mRNFL & $A D$ & Thinning \\
\hline $\begin{array}{l}\text { Berisha et al. } \\
{[42]}\end{array}$ & 2007 & pRNFL & $A D$ & Thinner in the superior quadrant \\
\hline Lu et al. [43] & 2010 & pRNFL & $A D$ & Thinner in the superior and inferior quadrants \\
\hline $\begin{array}{l}\text { Moschos et al. } \\
{[44]}\end{array}$ & 2012 & pRNFL & $A D$ & Thinning \\
\hline $\begin{array}{l}\text { Kirbas et al. } \\
{[45]}\end{array}$ & 2013 & pRNFL & $A D$ & Thinner in the superior quadrant \\
\hline $\begin{array}{l}\text { Marziani E } \\
\text { et al. [46] }\end{array}$ & 2013 & $\begin{array}{l}\text { mRNFL } \\
\text { mRNFL + GCL }\end{array}$ & $A D$ & Thinning \\
\hline $\begin{array}{l}\text { Garcia-Martin } \\
\text { et al. [47] }\end{array}$ & 2016 & $\begin{array}{l}\text { PRNFL, mRNFL GCL, IPL, } \\
\text { INL, OPL, ONL, RPE }\end{array}$ & $A D$ & Thinner pRNFL, mRNFL, GCL, and IPL \\
\hline $\begin{array}{l}\text { Gharbiya et al. } \\
\text { [48] }\end{array}$ & 2014 & pRNFL & $A D$ & No difference \\
\hline $\begin{array}{l}\text { Larrosa et al. } \\
{[49]}\end{array}$ & 2014 & pRNFL & $A D$ & Thinning except the nasal quadrant. \\
\hline $\begin{array}{l}\text { Kromer et al. } \\
{[50]}\end{array}$ & 2014 & pRNFL & $A D$ & Thinner in the nasal superior sector \\
\hline $\begin{array}{l}\text { Polo V et al. } \\
{[51]}\end{array}$ & 2017 & pRNFL & $A D$ & Thinner in the superior and inferior quadrants. \\
\hline $\begin{array}{l}\text { Salobrar- } \\
\text { Garcia et al. } \\
\text { [52] }\end{array}$ & 2015 & pRNFL, mRNFL & $A D$ & Thinner mRNFL \\
\hline $\begin{array}{l}\text { Eraslan et al. } \\
\text { [53] }\end{array}$ & 2015 & pRNFL, GCC & $A D$ & Thinning \\
\hline $\begin{array}{l}\text { La Morgia } \\
\text { et al. [54] }\end{array}$ & 2016 & pRNFL & $A D$ & Thinning \\
\hline $\begin{array}{l}\text { Cunha et al. } \\
{[55]}\end{array}$ & 2017 & pRNFL & $A D$ & Thinner in the temporal superior quadrants and globally \\
\hline Liu et al. [56] & 2015 & pRNFL & $A D$ & $\begin{array}{l}\text { Mild and moderate AD had thinner pRNFL in the superior quadrant. Severe AD } \\
\text { had thinner pRNFL in the superior and inferior quadrants. }\end{array}$ \\
\hline $\begin{array}{l}\text { Ferrari } L \text { et al. } \\
{[57]}\end{array}$ & 2017 & pRNFL, pGC-IPL & $\begin{array}{l}\mathrm{AD} \\
\mathrm{MCl}\end{array}$ & $\begin{array}{l}\text { No difference in mild AD. Moderate AD had thinner pRNFL and pGC-IPL. MCl } \\
\text { had thinner pRNFL. }\end{array}$ \\
\hline $\begin{array}{l}\text { Paquet et al. } \\
\text { [58] }\end{array}$ & 2007 & pRNFL & $\begin{array}{l}\mathrm{AD} \\
\mathrm{MCl}\end{array}$ & Thinning \\
\hline $\begin{array}{l}\text { Kesler et al. } \\
{[59]}\end{array}$ & 2011 & pRNFL & $\begin{array}{l}\mathrm{AD} \\
\mathrm{MCl}\end{array}$ & $\begin{array}{l}\text { AD had thinner pRNFL in the superior and inferior quadrants. MCI had thinner } \\
\text { pRNFL only in the inferior quadrant. }\end{array}$ \\
\hline $\begin{array}{l}\text { Ascaso et al. } \\
{[60]}\end{array}$ & 2014 & pRNFL & $\begin{array}{l}\mathrm{AD} \\
\mathrm{MCl}\end{array}$ & $\begin{array}{l}\text { AD had thinner pRNFL in all sectors. MCI had thinner pRNFL in all sectors } \\
\text { except the temporal quadrant. }\end{array}$ \\
\hline Gao et al. [61] & 2015 & pRNFL & $\begin{array}{l}\mathrm{AD} \\
\mathrm{MCl}\end{array}$ & Thinning \\
\hline $\begin{array}{l}\text { Oktem et al. } \\
\text { [62] }\end{array}$ & 2015 & pRNFL & $\begin{array}{l}\mathrm{AD} \\
\mathrm{MCl}\end{array}$ & Thinning \\
\hline $\begin{array}{l}\text { Cheung et al. } \\
\text { [63] }\end{array}$ & 2015 & pRNFL, GC-IPL & $\begin{array}{l}\mathrm{AD} \\
\mathrm{MCl}\end{array}$ & $\begin{array}{l}\text { AD had thinner PRNFL in the superior quadrant and thinner } \mathrm{mGC-IPL} \text { in all } \\
\text { sectors. } \\
\mathrm{MCl} \text { had thinner } \mathrm{MGC-IPL} \text { in the majority of sectors. }\end{array}$ \\
\hline $\begin{array}{l}\text { Shao et al. } \\
{[64]}\end{array}$ & 2018 & pRNFL, GC-IPL & $\begin{array}{l}\mathrm{AD} \\
\mathrm{MCl}\end{array}$ & Thinning \\
\hline $\begin{array}{l}\text { Almeida et al. } \\
\text { [65] }\end{array}$ & 2019 & pRNFL, mRNFL & $\mathrm{MCl}$ & Thinner mRNFL, mGC-IPL and mGCC \\
\hline Santos et al. & 2018 & pRNFL, mRNFL, GCL, IPL, & Preclinical & Thinner mRNFL, ONL and IPL \\
\hline
\end{tabular}


Table 1 Studies on OCT parameters in patients with AD, MCl and preclinical AD (Continued)

\begin{tabular}{|c|c|c|c|c|}
\hline Authors & $\begin{array}{l}\text { Year of } \\
\text { publication }\end{array}$ & Layer & Subjects & Alteration \\
\hline [66] & & $\mathrm{OPL}, \mathrm{INL}, \mathrm{ONL}$ & $A D$ & \\
\hline $\begin{array}{l}\text { López-Cuenca } \\
\text { et al. [67] }\end{array}$ & 2020 & $\begin{array}{l}\text { pRNFL, mRNFL, GCL, IPL, } \\
\text { INL, OPL, ONL, RPE }\end{array}$ & $\begin{array}{l}\text { Preclinical } \\
\text { AD }\end{array}$ & Thinner mRNFL, IPL, INL and OPL \\
\hline $\begin{array}{l}\text { Snyder et al. } \\
\text { [68] }\end{array}$ & 2016 & $\begin{array}{l}\text { pRNFL, mRNFL, GCL, IPL, } \\
\text { INL, OPL, ONL, }\end{array}$ & $\begin{array}{l}\text { Preclinical } \\
A D\end{array}$ & Thicker IPL \\
\hline $\begin{array}{l}\text { van de Kreeke } \\
\text { et al. [69] }\end{array}$ & 2019 & pRNFL, mRNFL, GCL, IPL, & $\begin{array}{l}\text { Preclinical } \\
A D\end{array}$ & No difference \\
\hline $\begin{array}{l}\text { van de Kreeke } \\
\text { et al. [70] }\end{array}$ & 2020 & pRNFL, mRNFL, GCL, IPL, & $\begin{array}{l}\text { Preclinical } \\
\text { AD }\end{array}$ & No difference in the rate of change of any retinal layers \\
\hline
\end{tabular}

OCT optical coherence tomography; $A D$ Alzheimer's disease; $M C I$ mild cognitive impairment; $p R N F L$ peripapillary retinal nerve fiber layer; $m R N F L$ macular retinal nerve fiber layer; GCL ganglion cell layer; IPL inner plexiform layer; GC-IPL ganglion cell-inner plexiform layer; $p G C$-IPL peripapillary ganglion cell-inner plexiform layer; $m G C C$ macular ganglion cell complex; INL inner nuclear layer; OPL outer plexiform layer; ONL outer nuclear layer; RPE retinal pigment epithelium

and moderate $\mathrm{AD}$ patients, compared to the controls. In severe $\mathrm{AD}$, the loss of pRNFL occurred not only in the superior quadrant but also in the inferior quadrant. Others have pointed out that the size of the RGC is 10 to 20 times the diameter of axons, which may lead to more significant changes in the thickness of GC-IPL and GCC compared to the pRNFL [63]. Several studies have also found changes in the GC-IPL and GCC in AD. Significant thinning of the average GCC has been associated with $\mathrm{AD}$ [53]. A recent meta-analysis also showed that the average thickness of GC-IPL was significantly decreased in $\mathrm{AD}$ and the thinning occurred in most sectors around the fovea, except the supratemporal sector [81]. In addition, a series of studies has shown that the cognitive scores are significantly correlated with macular parameters rather than the pRNFL thickness [41, 57, 65]. A large population-based study in Japan discovered that the presence of dementia was inversely associated with full macular thickness and GCC thickness but not with the pRNFL thickness [82]. Another populationbased study in Germany also showed that the GCC volume was more strongly related to the global function than was the pRNFL thickness [83]. In line with the above results, some also inferred that the GCC thickness performed better than pRNFL thickness in detecting the disease status based on the area under the curve value [84]. The divisions of the retina seem to have better diagnostic performance due to the less influence from individual variation [85]. These results indicate that the macular parameters are more useful than peripapillary parameters.

Similarly, pRNFL, GC-IPL or GCC thinning has also been found in MCI patients [56-64, 79, 86]. Others even discovered thickening and thinning of regions adjacent to each other in MCI patients, indicating that the two layers undergo dynamic changes during progression

Table 2 Studies on OCTA parameters in patients with $A D, M C l$ and preclinical $A D$

\begin{tabular}{|c|c|c|c|c|}
\hline Authors & $\begin{array}{l}\text { Year of } \\
\text { publication }\end{array}$ & Parameters & Subjects & Alteration \\
\hline $\begin{array}{l}\text { Bulut } M \text { et al. } \\
\text { [71] }\end{array}$ & 2018 & SRCP-VD, DRCP-VD, FAZ & $A D$ & Lower VD, enlarged FAZ. \\
\hline $\begin{array}{l}\text { Lahme L et al. } \\
{[72]}\end{array}$ & 2018 & $\begin{array}{l}\text { SRCP-flow density, DRCP-flow dens- } \\
\text { ity, Peripapillary-VD }\end{array}$ & $A D$ & Lower SRCP-flow density \\
\hline Jiang et al. [73] & 2017 & SRCP-VD, DRCP-VD & $\begin{array}{l}\mathrm{AD} \\
\mathrm{MCl}\end{array}$ & $\begin{array}{l}\text { AD had lower VD of SRCP and DRCP. MCI had lower VD of } \\
\text { DRCP in the superior nasal quadrant }\end{array}$ \\
\hline $\begin{array}{l}\text { Stephen P et al. } \\
{[74]}\end{array}$ & 2019 & SRCP-VD, FAZ & $\begin{array}{l}\mathrm{AD} \\
\mathrm{MCl}\end{array}$ & AD had lower SRCP-VD. No difference in $\mathrm{MCl}$ \\
\hline $\begin{array}{l}\text { Zhang et al. } \\
{[75]}\end{array}$ & 2019 & SRCP-VD, DRCP-VD, RPC & $\begin{array}{l}\mathrm{MCl} \text { or } \\
\text { early } \mathrm{AD}\end{array}$ & Lower SRCP-VD \\
\hline Wu et al. [76] & 2020 & SRCP-VD, DRCP-VD, FAZ & $\begin{array}{l}\mathrm{AD} \\
\mathrm{MCl}\end{array}$ & Lower DRCP-VD \\
\hline $\begin{array}{l}\text { O'Bryhim et al. } \\
\text { [77] }\end{array}$ & 2018 & SRCP-VD, FAZ & $\begin{array}{l}\text { Preclinical } \\
\mathrm{AD}\end{array}$ & Lower VD, enlarged FAZ \\
\hline $\begin{array}{l}\text { van de Kreeke } \\
\text { et al. [78] }\end{array}$ & 2020 & Macular-VD, Peripapillary-VD, FAZ & $\begin{array}{l}\text { Preclinical } \\
\text { AD }\end{array}$ & Higher VD, no difference in FAZ. \\
\hline
\end{tabular}

OCT optical coherence tomography; $A D$ Alzheimer's disease; $M C I$ mild cognitive impairment; $S R C P$-VD superficial retinal capillary plexus-vessel density; $D R C P$-VD deep retinal capillary plexus-vessel density; RPC radial peripapillary capillary; $F A Z$ foveal avascular zone 
from MCI to $\mathrm{AD}$ [87]. Interestingly, the mean thickness of GC-IPL and GCC in MCI patients is significantly reduced compared with that in controls, while changes in the pRNFL thickness are not significant [65]. The above findings suggest that the ganglion cells around macula, reflected by the thickness of GC-IPL or GCC, are sensitive in detecting neural structural changes in the initial stage of MCI.

In addition, a 27-month longitudinal study on preclinical AD showed significant changes in macular RNFL (mRNFL) rather than pRNFL over time [66]. The mRNFL thinning was significantly correlated with increased neocortical accumulation of $\mathrm{A} \beta$ and impaired performance in a task of audiovisual integration efficiency. Another study also suggested that the axonal loss in the mRNFL occurred earlier than pRNFL degeneration and this retinal parameter was expected to reflect the subtle disruption of white matter integrity in the preclinical AD stage [67]. However, several other studies did not report similar significant results $[68,69]$. Current cross-sectional studies have reported no statistically significant differences in the pRNFL or GCL between preclinical AD and controls. A longitudinal follow-up study also showed no difference in the rate of change of the above layers [70]. Therefore, the diagnostic efficacy of retinal neural structural parameters and their relationship with the progression of AD should be further studied especially in the preclinical $\mathrm{AD}$ stage.

Other retinal layer changes in $A D, M C l$, and preclinical $A D$ In additional to the neurodegenerative changes, neuroinflammation in retina and brain is also involved in $\mathrm{AD}$ progression [88]. Retinal glial cells including Muller cells, astrocytes and microglia cells are involved in immune and inflammatory responses and may lead to changes in the outer layer of the retina. The outer layer is relatively less studied and the results are inconsistent. Some studies in AD patients have found remarkable thickening of the ONL [64, 89], while others revealed no significant decrease of the outer retinal thickness including the ONL [90]. Furthermore, there is no significant difference in IPL and INL, albeit with OPL thinning [89]. However, inconsistent with the above results based on OCT devices, postmortem examination of retinas of AD patients showed thinning of pRNFL, GCL, IPL, INL, OPL and ONL [91]. The researchers further pointed out that the retinal structural damage may be attributed to the retrograde trans-synaptic degeneration, deposition of $\mathrm{A} \beta$ plaques, as well as the consequent neurotoxicity.

In MCI subjects, some studies have found OPL thinning and ONL thickening [89], while others revealed no significant difference in the ONL [90]. Only a few studies have focused on the outer retinal layers in preclinical $\mathrm{AD}$ and the results are controversial. A recent study found significant decreases in the IPL, INL and OPL in $A p o E$ \&4 carriers with a family history of AD compared to the non-carriers without a family history [67]. Another study also showed a decrease in IPL and ONL volumes over a 27-month follow-up in older adults with multiple risk factors for $\mathrm{AD}$, compared to the healthy control subjects [66]. Inconsistently, a cross-sectional study reported no significant differences in INL, ONL and OPL [68]. Besides, remarkable IPL thickening has been reported as well. As for IPL, a team showed no difference in cross-sectional observation or in the rate of change $[69,70]$. These findings suggest that the individual retinal layers play different roles at different stages of $\mathrm{AD}$, and the thickening and thinning of the outer layer, which contains a variety of cells, is not specific compared to the RNFL and GCC. Of course, the differences in diagnostic criteria, inclusion and exclusion criteria, and devices may lead to the heterogeneity of the results. Further large longitudinal studies are needed to confirm the effectiveness of individual retinal layers, especially in the preclinical AD stage.

\section{Retinal microvascular changes in $A D, M C l$ and preclinical AD}

Retinal microvascular OCTA findings are relatively less reported. In general, retinal microvascular damage can be observed at all stages of $\mathrm{AD}$. A report on monozygotic twin pairs showed significantly decreased $V D$ in the superficial retinal capillary plexus (SRCP) in twins with $\mathrm{AD}$ compared with cognitively normal twins, indicating that the changes of SRCP may serve as a possible biomarker for AD based on OCTA [92]. Several recent studies have also shown decreased SRCP or deep retinal capillary plexus (DRCP), as well as enlarged foveal avascular zone (FAZ) in AD subjects $[71-74,76]$. The FAZ enlargement may be due to the dropout of vasculature within the fovea. Besides, a significantly reduced flow density in radial peripapillary capillaries (RPC) with larger vascular channels in the peripapillary region has also been found in $\mathrm{AD}$ patients [72]. Most studies found that the vascular parameters were significantly correlated with cognitive scores [71, 74-77]. However, some studies also showed no association between retinal vascular parameters and cognitive function [72, 73]. The inconsistency may result from ambiguous clinical staging of disease progression with a small sample size.

In addition, some studies have shown a tendency of microvascular density loss along the development of $\mathrm{AD}$, which indicates that the retinal vascular impairment reflected as reduced microvascular density by OCTA can serve as a marker for monitoring disease progression [73]. Meanwhile, MCI individuals had significantly declined parafoveal SRCP VD and adjusted flow index, while no difference was found in the RPC [75]. Contrary to the above study, other studies have demonstrated no 
statistically significant difference in SRCP VD [73, 74, 76]. Interestingly, two studies found lower microvascular density in DRCP rather than in SRCP in MCI patients $[73,76]$. This may be because that the smaller microvasculature of the DRCP is more susceptible to disease development than larger vessels of the SRCP, suggesting that the deep microvascular density around macula is more sensitive in detecting and monitoring progression of MCI at the early stage.

So far, there are only two relevant studies focusing on preclinical AD. Notably, one study revealed enlargement of the FAZ in individuals with preclinical AD with positive positron emission tomography scan biomarkers [77]. However, the other showed no statistical difference in FAZ size between preclinical AD and healthy individuals. Even more, they found increased vessel density in preclinical $\mathrm{AD}$ subjects, which may be caused by the increased blood flow secondary to hypoxia [78].

In sum, research on the role of microvascular pathology as reflected by OCTA in early diagnosis of AD is still in the preliminary stage. The relationship between vascular change and neurodegenerative changes needs to be further investigated in more studies with longer follow-up durations.

\section{Conclusion}

In conclusion, accumulating evidence has shown that the retina could provide valuable insights into the early diagnosis of $\mathrm{AD}$. Retinal neuronal structural and microvascular imaging by OCT/OCTA is potentially useful for large-scale population screening or monitoring responses to therapies in AD patients. Before full application in clinical practice, further research is needed to validate whether the findings on retinal neuronal loss and microvascular damage in $\mathrm{MCI}$ or even in preclinical $\mathrm{AD}$ patients are related with the progression of cognitive impairment and brain neuronal/vascular loss in individual $\mathrm{AD}$ patients, based on longitudinal data of multi-center studies. Histopathological studies are also needed to understand the pathophysiological mechanisms underlying the retinal neuronal and microvascular alterations, which will facilitate the clinical applications of retinal OCT/OCTA imaging in large-scale population screening and monitoring and the development of new therapies.

\footnotetext{
Abbreviations

AD: Alzheimer's disease; MCl: Mild cognitive impairment; OCT: Optical coherence tomography; OCTA: Optical coherence tomography angiography; MRI: Magnetic resonance imaging; CT: Computed tomography; RNFL: Retinal nerve fiber layer; GCL: Ganglion cell layer; IPL: Inner plexiform layer; INL: Inner nuclear layer; OPL: Outer plexiform layer; ONL: Outer nuclear layer; GCIPL: Ganglion cell-inner plexiform layer; GCC: Ganglion cell complex; pRNFL: Peripapillary retinal nerve fiber layer; mRNFL: Macular retinal nerve fiber layer; VD: Vessel density; FD: Fractal dimension; FAZ: Foveal avascular zone; VLD: Vessel length density; RPC: Radial peripapillary capillary; SRCP: Superficial retinal capillary plexus; DRCP: Deep retinal capillary plexus; Aß: Amyloid-beta
}

\section{Acknowledgements}

Not applicable.

Authors' contributions

All authors participated in drafting the manuscript. All authors read and approved the final manuscript.

\section{Funding}

No funding.

Availability of data and materials

Not applicable.

Ethics approval and consent to participate

Not applicable.

\section{Consent for publication}

Not applicable.

\section{Competing interests}

All authors claim that there are no conflicts of interest.

\section{Author details}

${ }^{1}$ School of Ophthalmology and Optometry, Wenzhou Medical College, Wenzhou 325027, China. ${ }^{2}$ Department of Neurology, Daping Hospital, Third Military Medical University, Chongqing 400042, China.

Received: 20 August 2020 Accepted: 7 January 2021

Published online: 01 February 2021

References

1. Perl DP. Neuropathology of Alzheimer's disease. Mt Sinai J Med. 2010;77:3242.

2. Savva GM, Wharton SB, Ince PG, Forster G, Matthews FE, Brayne C. Age, neuropathology, and dementia. N Engl J Med. 2009;360:2302-9.

3. Ramirez Al, de Hoz R, Salobrar-Garcia E, Salazar JJ, Rojas B, Ajoy D, et al. The role of microglia in retinal neurodegeneration: Alzheimer's disease, Parkinson, and glaucoma. Front Aging Neurosci. 2017;9:214.

4. Fernández-Albarral JA, Salobrar-García E, Martínez-Páramo R, Ramírez Al, de Hoz R, Ramírez JM, et al. Retinal glial changes in Alzheimer's disease - a review. J Optom. 2019;12:198-207.

5. Prince M, Wimo A, Guerchet M, Ali GC, Wu YT, Prina M, et al. World Alzheimer Report 2015. The Global Impact of Dementia: An Analysis of Prevalence, Incidence, Cost and Trends. London: Alzheimer's Disease International (ADI); 2015.

6. Brookmeyer R, Johnson E, Ziegler-Graham K, Arrighi HM. Forecasting the global burden of Alzheimer's disease. Alzheimers Dement. 2007;3:186-91.

7. Martínez G, Vernooij RW, Fuentes Padilla P, Zamora J, Flicker L, Bonfill CX. ${ }^{18} \mathrm{~F}$ PET with flutemetamol for the early diagnosis of Alzheimer's disease dementia and other dementias in people with mild cognitive impairment (MCI). Cochrane Database Syst Rev. 2017;11:Cd012884.

8. Rabinovici GD, Gatsonis C, Apgar C, Chaudhary K, Gareen I, Hanna L, et al. Association of amyloid positron emission tomography with subsequent change in clinical management among medicare beneficiaries with mild cognitive impairment or dementia. JAMA. 2019;321:1286-94.

9. Kaerst L, Kuhlmann A, Wedekind D, Stoeck K, Lange P, Zerr I. Using cerebrospinal fluid marker profiles in clinical diagnosis of dementia with Lewy bodies, Parkinson's disease, and Alzheimer's disease. J Alzheimers Dis. 2014;38:63-73.

10. Struyfs $H$, Van Broeck B, Timmers M, Fransen E, Sleegers $K$, Van Broeckhoven $C$, et al. Diagnostic accuracy of cerebrospinal fluid amyloid- $\beta$ isoforms for early and differential dementia diagnosis. J Alzheimers Dis. 2015;45:813-22.

11. Koronyo Y, Biggs D, Barron E, Boyer DS, Pearlman JA, Au WJ, et al. Retinal amyloid pathology and proof-of-concept imaging trial in Alzheimer's disease. JCl Insight. 2017;2.

12. Shi Z, Cao X, Hu J, Jiang L, Mei X, Zheng H, et al. Retinal nerve fiber layer thickness is associated with hippocampus and lingual gyrus volumes in nondemented older adults. Prog Neuro-Psychopharmacol Biol Psychiatry. 2020;99:109824. 
13. Shi Z, Zheng H, Hu J, Jiang $L$, Cao X, Chen $Y$, et al. Retinal nerve fiber layer thinning is associated with brain atrophy: a longitudinal study in nondemented older adults. Front Aging Neurosci. 2019;11:69.

14. Gommer ED, Martens EG, Aalten P, Shijaku E, Verhey FR, Mess WH, et al. Dynamic cerebral autoregulation in subjects with Alzheimer's disease, mild cognitive impairment, and controls: evidence for increased peripheral vascular resistance with possible predictive value. J Alzheimers Dis. 2012;30:805-13.

15. Lin YF, Smith AV, Aspelund T, Betensky RA, Smoller JW, Gudnason V, et al. Genetic overlap between vascular pathologies and Alzheimer's dementia and potential causal mechanisms. Alzheimers Dement. 2019;15:65-75.

16. Patton N, Aslam T, Macgillivray T, Pattie A, Deary IJ, Dhillon B. Retinal vascular image analysis as a potential screening tool for cerebrovascular disease: a rationale based on homology between cerebral and retinal microvasculatures. J Anat. 2005;206:319-48.

17. Ong YT, Hilal S, Cheung CY, Venketasubramanian N, Niessen WJ, Vrooman $\mathrm{H}$, et al. Retinal neurodegeneration on optical coherence tomography and cerebral atrophy. Neurosci Lett. 2015;584:12-6.

18. Hayreh SS. The 1994 Von Sallman lecture. The optic nerve head circulation in health and disease. Exp Eye Res. 1995;61:259-72.

19. Hayreh SS. The blood supply of the optic nerve head and the evaluation of it - myth and reality. Prog Retin Eye Res. 2001;20:563-93.

20. Ryan SJ, Sadda SR. Ryan's retinal imaging and diagnostics (1st Ed.). Saunders; 2013

21. JMea R. Glia and blood retinal barrier: effects of ocular hypertension. In: Cardiovascular Disease II. iConcept Press Ltd; 2014.

22. Koronyo-Hamaoui M, Koronyo Y, Ljubimov AV, Miller CA, Ko MK, Black KL, et al. Identification of amyloid plaques in retinas from Alzheimer's patients and noninvasive in vivo optical imaging of retinal plaques in a mouse model. Neuroimage. 2011;54(Suppl 1):S204-17.

23. Entezari M, Azhari S, Ramezani A. Fundus findings in spontaneous subarachnoid hemorrhage and their correlation with neurologic characteristics. Eur J Ophthalmol. 2009;19:460-5.

24. Rhee EJ, Chung PW, Wong TY, Song SJ. Relationship of retinal vascular caliber variation with intracranial arterial stenosis. Microvasc Res. 2016;108:64-8.

25. Huang D, Swanson EA, Lin CP, Schuman JS, Stinson WG, Chang W, et al. Optical coherence tomography. Science. 1991;254:1178-81.

26. Pazos M, Dyrda AA, Biarnés M, Gómez A, Martín C, Mora C, et al. Diagnostic accuracy of Spectralis SD OCT automated macular layers segmentation to discriminate normal from early glaucomatous eyes. Ophthalmology. 2017; 124:1218-28.

27. Frost S, Kanagasingam Y, Sohrabi H, Vignarajan J, Bourgeat P, Salvado O, et al. Retinal vascular biomarkers for early detection and monitoring of Alzheimer's disease. Transl Psychiatry. 2013;3:e233.

28. Deal JA, Sharrett AR, Rawlings AM, Gottesman RF, Bandeen-Roche K, Albert $M$, et al. Retinal signs and 20-year cognitive decline in the atherosclerosis risk in communities study. Neurology. 2018;90:e1158-66.

29. McGrory S, Ballerini L, Okely JA, Ritchie SJ, Doubal FN, Doney AS, et al. Retinal microvascular features and cognitive change in the Lothian-birth cohort 1936. Alzheimers Dement (Amst). 2019;11:500-9.

30. McGrory S, Cameron JR, Pellegrini E, Warren C, Doubal FN, Deary IJ, et al. The application of retinal fundus camera imaging in dementia: a systematic review. Alzheimers Dement (Amst). 2017;6:91-107.

31. Lee CS, Tyring AJ, Wu Y, Xiao S, Rokem AS, DeRuyter NP, et al. Generating retinal flow maps from structural optical coherence tomography with artificial intelligence. Sci Rep. 2019;9:5694.

32. Jung NY, Han JC, Ong YT, Cheung CY, Chen CP, Wong TY, et al. Retinal microvasculature changes in amyloid-negative subcortical vascular cognitive impairment compared to amyloid-positive Alzheimer's disease. J Neurol Sci. 2019;396:94-101.

33. Jia Y, Tan O, Tokayer J, Potsaid B, Wang Y, Liu JJ, et al. Split-spectrum amplitude-decorrelation angiography with optical coherence tomography. Opt Express. 2012;20:4710-25.

34. Spaide RF, Klancnik Jr JM Jr, Cooney MJ. Retinal vascular layers imaged by fluorescein angiography and optical coherence tomography angiography. JAMA Ophthalmol. 2015;133:45-50.

35. Kashani AH, Chen CL, Gahm JK, Zheng F, Richter GM, Rosenfeld PJ, et al. Optical coherence tomography angiography: a comprehensive review of current methods and clinical applications. Prog Retin Eye Res. 2017;60:66-100.

36. Savastano MC, Lumbroso B, Rispoli M. In vivo characterization of retinal vascularization morphology using optical coherence tomography angiography. Retina. 2015;35:2196-203.
37. Jiang H, Debuc DC, Rundek T, Lam BL, Wright CB, Shen M, et al. Automated segmentation and fractal analysis of high-resolution non-invasive capillary perfusion maps of the human retina. Microvasc Res. 2013;89:172-5.

38. Chen $\mathrm{Q}, \mathrm{Ma} \mathrm{Q}, \mathrm{Wu}$ C, Tan F, Chen F, Wu Q, et al. Macular vascular fractal dimension in the deep capillary layer as an early indicator of microvascular loss for retinopathy in type 2 diabetic patients. Invest Ophthalmol Vis Sci. 2017;58:3785-94.

39. Shi C, Chen Y, Kwapong WR, Tong Q, Wu S, Zhou Y, et al. Characterization by fractal dimension analysis of the retinal capillary network in Parkinson disease. Retina. 2020;40:1483-91.

40. Parisi V, Restuccia R, Fattapposta F, Mina C, Bucci MG, Pierelli F. Morphological and functional retinal impairment in Alzheimer's disease patients. Clin Neurophysiol. 2001;112:1860-7.

41. Iseri PK, Altinaş O, Tokay T, Yüksel N. Relationship between cognitive impairment and retinal morphological and visual functional abnormalities in Alzheimer disease. J Neuroophthalmol. 2006;26:18-24.

42. Berisha F, Feke GT, Trempe CL, McMeel JW, Schepens CL. Retinal abnormalities in early Alzheimer's disease. Invest Ophthalmol Vis Sci. 2007; 48:2285-9.

43. Lu Y, Li Z, Zhang X, Ming B, Jia J, Wang R, et al. Retinal nerve fiber layer structure abnormalities in early Alzheimer's disease: evidence in optical coherence tomography. Neurosci Lett. 2010;480:69-72.

44. Moschos MM, Markopoulos I, Chatziralli I, Rouvas A, Papageorgiou SG, Ladas I, et al. Structural and functional impairment of the retina and optic nerve in Alzheimer's disease. Curr Alzheimer Res. 2012;9:782-8.

45. Kirbas S, Turkyilmaz K, Anlar O, Tufekci A, Durmus M. Retinal nerve fiber layer thickness in patients with Alzheimer disease. J Neuroophthalmol. 2013; 33:58-61.

46. Marziani E, Pomati S, Ramolfo P, Cigada M, Giani A, Mariani C, et al. Evaluation of retinal nerve fiber layer and ganglion cell layer thickness in Alzheimer's disease using spectral-domain optical coherence tomography. Invest Ophthalmol Vis Sci. 2013;54:5953-8.

47. Garcia-Martin E, Bambo MP, Marques ML, Satue M, Otin S, Larrosa JM, et al. Ganglion cell layer measurements correlate with disease severity in patients with Alzheimer's disease. Acta Ophthalmol. 2016;94:e454-9.

48. Gharbiya M, Trebbastoni A, Parisi F, Manganiello S, Cruciani F, D'Antonio F, et al. Choroidal thinning as a new finding in Alzheimer's disease: evidence from enhanced depth imaging spectral domain optical coherence tomography. J Alzheimers Dis. 2014;40:907-17.

49. Larrosa JM, Garcia-Martin E, Bambo MP, Pinilla J, Polo V, Otin S, et al. Potential new diagnostic tool for Alzheimer's disease using a linear discriminant function for Fourier domain optical coherence tomography. Invest Ophthalmol Vis Sci. 2014;55:3043-51.

50. Kromer R, Serbecic N, Hausner L, Froelich L, Aboul-Enein F, Beutelspacher SC. Detection of retinal nerve fiber layer defects in Alzheimer's disease using SD-OCT. Front Psychiatry. 2014;5:22.

51. Polo V, Rodrigo MJ, Garcia-Martin E, Otin S, Larrosa JM, Fuertes MI, et al. Visual dysfunction and its correlation with retinal changes in patients with Alzheimer's disease. Eye (Lond). 2017;31:1034-41.

52. Salobrar-Garcia E, Hoyas I, Leal M, de Hoz R, Rojas B, Ramirez Al, et al. Analysis of retinal peripapillary segmentation in early Alzheimer's disease patients. Biomed Res Int. 2015;2015:636548.

53. Eraslan M, Çerman E, Çekiç O, Balci S, Dericioğlu V, Sahin Ö, et al. Neurodegeneration in ocular and central nervous systems: optical coherence tomography study in normal-tension glaucoma and Alzheimer disease. Turk Med Sci. 2015;45:1106-14.

54. La Morgia C, Ross-Cisneros FN, Koronyo Y, Hannibal J, Gallassi R, Cantalupo $\mathrm{G}$, et al. Melanopsin retinal ganglion cell loss in Alzheimer disease. Ann Neurol. 2016;79:90-109.

55. Cunha JP, Proenca R, Dias-Santos A, Almeida R, Águas H, Alves M, et al. OCT in Alzheimer's disease: thinning of the RNFL and superior hemiretina. Graefes Arch Clin Exp Ophthalmol. 2017;255:1827-35.

56. Liu D, Zhang L, Li Z, Zhang $X, W u$ Y, Yang H, et al. Thinner changes of the retinal nerve fiber layer in patients with mild cognitive impairment and Alzheimer's disease. BMC Neurol. 2015;15:14

57. Ferrari L, Huang SC, Magnani G, Ambrosi A, Comi G, Leocani L. Optical coherence tomography reveals retinal neuroaxonal thinning in frontotemporal dementia as in Alzheimer's disease. J Alzheimers Dis. 2017;56:1101-7.

58. Paquet C, Boissonnot M, Roger F, Dighiero P, Gil R, Hugon J. Abnormal retinal thickness in patients with mild cognitive impairment and Alzheimer's disease. Neurosci Lett. 2007;420:97-9. 
59. Kesler A, Vakhapova V, Korczyn AD, Naftaliev E, Neudorfer M. Retinal thickness in patients with mild cognitive impairment and Alzheimer's disease. Clin Neurol Neurosurg. 2011;113:523-6.

60. Ascaso FJ, Cruz N, Modrego PJ, Santabárbara J, Pascual LF, Lobo A, et al. Retinal alterations in mild cognitive impairment and Alzheimer's disease: an optical coherence tomography study. J Neurol. 2014;261:1522-30.

61. Gao L, Liu Y, Li X, Bai Q, Liu P. Abnormal retinal nerve fiber layer thickness and macula lutea in patients with mild cognitive impairment and Alzheimer's disease. Arch Gerontol Geriatr. 2015;60:162-7.

62. Oktem EO, Derle E, Kibaroglu S, Oktem C, Akkoyun I, Can U. The relationship between the degree of cognitive impairment and retinal nerve fiber layer thickness. Neurol Sci. 2015;36:1141-6.

63. Cheung CY, Ong YT, Hilal S, Ikram MK, Low S, Ong YL, et al. Retinal ganglion cell analysis using high-definition optical coherence tomography in patients with mild cognitive impairment and Alzheimer's disease. J Alzheimers Dis 2015:45:45-56

64. Shao $Y$, Jiang $H$, Wei $Y$, Shi $Y$, Shi $C$, Wright $C B$, et al. Visualization of focal thinning of the ganglion cell-inner plexiform layer in patients with mild cognitive impairment and Alzheimer's disease. J Alzheimers Dis. 2018;64 1261-73.

65. Almeida ALM, Pires LA, Figueiredo EA, Costa-Cunha LVF, Zacharias LC, Preti $\mathrm{RC}$, et al. Correlation between cognitive impairment and retinal neural loss assessed by swept-source optical coherence tomography in patients with mild cognitive impairment. Alzheimers Dement (Amst). 2019;11:659-69.

66. Santos CY, Johnson LN, Sinoff SE, Festa EK, Heindel WC, Snyder PJ. Change in retinal structural anatomy during the preclinical stage of Alzheimer's disease. Alzheimers Dement (Amst). 2018;10:196-209.

67. López-Cuenca I, de Hoz R, Salobrar-García E, Elvira-Hurtado L, Rojas P, Fernández-Albarral JA, et al. Macular thickness decrease in asymptomatic subjects at high genetic risk of developing Alzheimer's disease: an OCT study. J Clin Med. 2020;9:1728.

68. Snyder PJ, Johnson LN, Lim YY, Santos CY, Alber J, Maruff P, Fernández B, et al. Nonvascular retinal imaging markers of preclinical Alzheimer's disease. Alzheimers Dement (Amst). 2016;4:169-78.

69. van de Kreeke JA, Nguyen HT, den Haan J, Konijnenberg E, Tomassen J, den Braber A, et al. Retinal layer thickness in preclinical Alzheimer's disease. Acta Ophthalmol. 2019;97:798-804.

70. van de Kreeke JA, Nguyen HT, Konijnenberg E, Tomassen J, den Braber A, Ten Kate M, et al. Longitudinal retinal layer changes in preclinical Alzheimer's disease. Acta Ophthalmol. 2020;18.

71. Bulut M, Kurtulus F, Gozkaya O, Erol MK, Cengiz A, Akıdan M, et al. Evaluation of optical coherence tomography angiographic findings in Alzheimer's type dementia. Br J Ophthalmol. 2018;102:233-7.

72. Lahme L, Esser EL, Mihailovic N, Schubert F, Lauermann J, Johnen A, et al. Evaluation of ocular perfusion in Alzheimer's disease using optical coherence tomography angiography. J Alzheimers Dis. 2018;66:1745-52.

73. Jiang $H$, Wei $Y$, Shi $Y$, Wright $C B$, Sun $X$, Gregori G, et al. Altered macular microvasculature in mild cognitive impairment and Alzheimer disease. J Neuroophthalmol. 2018;38:292-8.

74. Yoon SP, Grewal DS, Thompson AC, Polascik BW, Dunn C, Burke JR, et al. Retinal microvascular and neurodegenerative changes in Alzheimer's disease and mild cognitive impairment compared with control participants. Ophthalmol Retina. 2019;3:489-99.

75. Zhang YS, Zhou N, Knoll BM, Samra S, Ward MR, Weintraub S, et al. Parafoveal vessel loss and correlation between peripapillary vessel density and cognitive performance in amnestic mild cognitive impairment and early Alzheimer's disease on optical coherence tomography angiography. PLoS One. 2019;14:e0214685.

76. Wu J, Zhang X, Azhati G, Li T, Xu G, Liu F. Retinal microvascular attenuation in mental cognitive impairment and Alzheimer's disease by optical coherence tomography angiography. Acta Ophthalmol. 2020;98:e781-7.

77. O'Bryhim BE, Apte RS, Kung N, Coble D, Van Stavern GP. Association of preclinical Alzheimer disease with optical coherence tomographic angiography findings. JAMA Ophthalmol. 2018;136:1242-8.

78. van de Kreeke JA, Nguyen HT, Konijnenberg E, Tomassen J, den Braber A, Ten Kate $M$, et al. Optical coherence tomography angiography in preclinical Alzheimer's disease. Br J Ophthalmol. 2020;104:157-61.

79. Thomson KL, Yeo JM, Waddell B, Cameron JR, Pal S. A systematic review and meta-analysis of retinal nerve fiber layer change in dementia, using optical coherence tomography. Alzheimers Dement (Amst). 2015;1:136-43.
80. Alber J, Goldfarb D, Thompson LI, Arthur E, Hernandez K, Cheng D, et al. Developing retinal biomarkers for the earliest stages of Alzheimer's disease: what we know, what we don't, and how to move forward. Alzheimers Dement. 2020;16:229-43.

81. Chan VTT, Sun Z, Tang S, Chen LJ, Wong A, Tham CC, et al. Spectral-domain OCT measurements in Alzheimer's disease: a systematic review and metaanalysis. Ophthalmology. 2019;126:497-510.

82. Ito Y, Sasaki M, Takahashi H, Nozaki S, Matsuguma S, Motomura K, et al. Quantitative assessment of the retina using OCT and associations with cognitive function. Ophthalmology. 2020;127:107-18.

83. Ward DD, Mauschitz MM, Bönniger MM, Merten N, Finger RP, Breteler MMB. Association of retinal layer measurements and adult cognitive function: a population-based study. Neurology. 2020;95:e1144-52

84. Sen S, Saxena R, Vibha D, Tripathi M, Sharma P, Phuljhele S, et al. Detection of structural and electrical disturbances in macula and optic nerve in Alzheimer's patients and their correlation with disease severity. Semin Ophthalmol. 2020:35:116-25.

85. Mwanza JC, Oakley JD, Budenz DL, Chang RT, Knight OJ, Feuer WJ. Macular ganglion cell-inner plexiform layer: automated detection and thickness reproducibility with spectral domain-optical coherence tomography in glaucoma. Invest Ophthalmol Vis Sci. 2011;52:8323-9.

86. Wu Y, Wang XN, Wang N, Han Y, Ma D, Lu Y. Regularity changes of the retinal nerve fiber layer and macular ganglion cell complex in patients with the amnestic mild cognitive impairment. Int J Neurosci. 2018;128:849-53.

87. Lad EM, Mukherjee D, Stinnett SS, Cousins SW, Potte GG, Burke JR, et al. Evaluation of inner retinal layers as biomarkers in mild cognitive impairment to moderate Alzheimer's disease. PLoS One. 2018;13:e0192646.

88. Nilson AN, English KC, Gerson JE, Barton Whittle T, Nicolas Crain C, et al. Tau oligomers associate with inflammation in the brain and retina of tauopathy mice and in neurodegenerative diseases. J Alzheimers Dis. 2017;55:1083-99.

89. Salobrar-García E, de Hoz R, Ramírez Al, López-Cuenca I, Rojas P, Vazirani R, et al. Changes in visual function and retinal structure in the progression of Alzheimer's disease. PLoS One. 2019:14:e0220535.

90. Uchida A, Pillai JA, Bermel R, Bonner-Jackson A, Rae-Grant A, Fernandez H, et al. Outer retinal assessment using spectral-domain optical coherence tomography in patients with Alzheimer's and Parkinson's disease. Invest Ophthalmol Vis Sci. 2018;59:2768-77.

91. Asanad S, Ross-Cisneros FN, Nassisi M, Barron E, Karanjia R, Sadun AA. The retina in Alzheimer's disease: histomorphometric analysis of an ophthalmologic biomarker. Invest Ophthalmol Vis Sci. 2019;60:1491-500.

92. Grewal DS, Polascik BW, Hoffmeyer GC, Fekrat S. Assessment of differences in retinal microvasculature using OCT angiography in Alzheimer's disease: a twin discordance report. Ophthalmic Surg Lasers Imaging Retina. 2018;49: $440-4$.

Ready to submit your research? Choose BMC and benefit from:

- fast, convenient online submission

- thorough peer review by experienced researchers in your field

- rapid publication on acceptance

- support for research data, including large and complex data types

- gold Open Access which fosters wider collaboration and increased citations

- maximum visibility for your research: over $100 \mathrm{M}$ website views per year

At $\mathrm{BMC}$, research is always in progress.

Learn more biomedcentral.com/submissions 